Article

\title{
Influence of Thiazolidine-2,4-Dione Derivatives with Azolidine or Thiosemicarbazone Moieties on Haemophilus spp. Planktonic or Biofilm-Forming Cells
}

\author{
Nazar Trotsko ${ }^{1, *}$, Urszula Kosikowska ${ }^{2}$, Sylwia Andrzejczuk ${ }^{2}$, Agata Paneth ${ }^{1}$ (D) and \\ Monika Wujec ${ }^{1}(\mathbb{D}$ \\ 1 Department of Organic Chemistry, Faculty of Pharmacy with Medical Analytics Division, Medical \\ University of Lublin, 4A Chodźki, 20-093 Lublin, Poland; agata.paneth@umlub.pl (A.P.); \\ monika.wujec@umlub.pl (M.W.) \\ 2 Department of Pharmaceutical Microbiology with Laboratory for Microbiological Diagnostics, \\ Faculty of Pharmacy with Medical Analytics Division, Medical University of Lublin, 1 Chodźki, \\ 20-093 Lublin, Poland; urszula.kosikowska@umlub.pl (U.K.); sylwia.andrzejczuk@umlub.pl (S.A.) \\ * Correspondence: nazar.trotsko@umlub.pl
}

Received: 18 February 2019; Accepted: 14 March 2019; Published: 17 March 2019

\begin{abstract}
Biofilm, naturally formed by microorganisms as integrated surface-bound communities, is one of the reasons for the development of antimicrobial resistance. Haemophilus spp. are common and representative opportunistic Gram-negative rods forming from the upper respiratory tract microbiota. The aim of this paper was to evaluate the influence of thiazolidine-2,4-dionebased azolidine and chlorophenylthiosemicarbazone hybrids against both planktonic and biofilm-forming Haemophilus spp. cells. The in vitro activity against planktonic and biofilm-forming cells of the tested compounds were evaluated by using the broth microdilution method. These activities were detected against reference and clinical strains of Haemophilus spp. on the basis of MICs (minimal inhibitory concentrations) and MBICs (minimal biofilm inhibitory concentrations). In addition, anti-adhesive properties of these compounds were examined. The target compounds showed potential activity against planktonic cells with MIC $=62.5-500 \mathrm{mg} / \mathrm{L}$ and biofilm-forming cells with MBIC $=62.5-1000 \mathrm{mg} / \mathrm{L}$. The observed anti-adhesive properties of the tested compounds were reversible during long-term incubation in a lower concentration of compounds.
\end{abstract}

Keywords: Haemophilus spp.; thiazolidine-2,4-dione based azolidine and chlorophenylthiosemicarbazone hybrids; anti-planktonic and antibiofilm activity; anti-adhesive properties

\section{Introduction}

One of the main problems of the effectiveness of antimicrobial therapy is the development of resistance to agents among both bacteria and fungi. It is an adaptive mechanism for self-survival.

Most bacteria and fungi naturally form biofilms as integrated surface-bound communities, which are important to survive in the host's body and in the natural environment. It is one of the reasons for the development of antimicrobial resistance. These structures are dynamic, integrated, both genetically and physiologically heterogenous, sedimentary multicellular communities, embedded in an extracellular biopolymer matrix [1]. Biofilms account for more than $80 \%$ of infectious diseases, which cause unpleasant wounds, ulcers, and lesions of the skin, mucous, membranes, and internal organs [2,3]. Additionally, biofilms cause chronic infections in tissues or by developing on the surfaces of medical biomaterials. 
Haemophilus spp. are common and representative opportunistic Gram-negative rods, representing bacteria forming from the upper respiratory tract microbiota. These fastidious bacteria, which grow in microaerophilic conditions (higher level of $\mathrm{CO}_{2}$ ), play a role in preventing the establishment of potential pathogens and are important for the human body condition [4,5]. Many species of haemophili normally reside in the airways and they can, rarely, cause infection in the respiratory tract, which can spread to other organs.

Haemophilus influenzae and some of the other Haemophilus species are commonly encountered in clinical microbiology laboratories and demonstrate a wide range of pathogenicity, from life-threatening invasive disease to respiratory infections to a nonpathogenic, commensal lifestyle. It is the most pathogenic bacteria colonizing the mucous membranes of the respiratory tract of young children or, sporadically, of elderly people. H. influenzae is frequently associated with different diseases (e.g., otitis media in children, sinusitis, conjunctivitis, chronic bronchitis, and pneumonia) and cause exacerbations in adults with chronic obstructive pulmonary disease [6]. Some of them, like bloodstream infections, are very serious.

In contrast to the accepted pathogenicity of $H$. influenzae, $H$. parainfluenzae is an opportunistic bacteria, with low pathogenicity that is highly adapted to the human airways [7,8]. Both H. influenzae and $H$. parainfluenzae occasionally, especially in immunocompromised people or after translocation in the body, can cause opportunistic acute, chronic, invasive, or non-invasive infections $[9,10]$.

Like many opportunistic pathogens inhabiting mammalian mucosal surfaces, non-typeable H. influenzae (NTHi) forms multicellular biofilm communities, both in vitro and in various infection models. These characteristics were also shown among $H$. parainfluenzae species isolated from healthy people, and from patients with various diseases [11,12]. It is known nowadays that these microorganisms may form a biofilm, which is the most prevalent mode of bacterial growth in nature and is a virulence determinant, which contributes to recurrent or chronic infections. Bacterial adhesion and their ability to growth in biofilm structure is a main problem in many environments (including biomedical, domestic, and natural) and for virulence properties of microorganisms with low pathogenicity. During the initial stage of biofilm formation (known as "early biofilm"), the adhesive properties of bacterial cells cause attachment to a colonizable surface (e.g., human tissue). Next, bacterial cells cause irreversible attachment to a surface, and a biofilm is established and matures ("mature biofilm") [13].

Both $H$. influenzae and $H$. parainfluenzae, as well as other haemophili diseases, are treated with various antimicrobials, mainly with beta-lactam antibiotics (including cephalosporins like ceftriaxone, cefotaxime, or cefuroxime, as well as amoxicillin-clavulanate), macrolides (e.g., azithromycin and clarithromycin), and fluoroquinolones. Which ones can be used depends on the location and severity of the infection and of the results of susceptibility tests. The CDC (Centers for Disease Control and Prevention) has guidelines for chemoprophylaxis for close contacts of $H$. influenzae type $b$ (Hib) cases, but does not have recommendations for the treatment of infections caused by species other than $H$. influenzae species [14]. The problem is observed for infections caused by other species of the genus Haemophilus, including opportunistic pathogens like NTHi and H. parainfluenzae, which, usually, can be the result of the local spread of microorganisms from the nasopharynx or after their translocation in the body. In the case of opportunistic infections caused by these bacteria, the cells' properties and the ability to grow a biofilm structure are important pathogenicity factors. Due to the increasing drug resistance of these bacteria, especially to beta-lactam antibiotics (the production of beta-lactamases due to changes in the cell wall structure) and the possibility of biofilm formation, it is necessary to look for new agents effective against these bacteria, both against planktonic and biofilm-forming cells $[15,16]$. Thiazolidine-2,4-dione (TZD) is a heterocyclic ring system, with multiple applications in medicinal chemistry through their wide range of biological activity. TZDs possess antidiabetic (glitazones drugs), aldose reductase inhibitory, anticancer, antibacterial, antifungal, and anti-inflammatory activities $[17,18]$. 
In a previous paper we described the antibacterial activity of TZD derivatives with azolidine and chlorophenylthiosemicarbazone moieties against aerobically-growing bacteria, like staphylococci or other Gram-positive microorganisms [19,20]. Evaluation of the influence of these compounds on the biofilm-forming and planktonic cells of fastidious and microaerophilic bacteria may be additional information required for the complete evaluation of their antibacterial potential. Especially as there are a few papers about anti-biofilm activity for TZD derivatives against both bacteria and fungi [21-28]. All of these derivatives are a group of 5-alkylidenethiazolidine-2,4-diones with $C_{6}-C_{12}$ alkyl chains. Most of the active compounds among this group, namely 5-octylidene-1,3-thiazolidine-2,4-dione (Thiazolidindione-8), inhibit fungal (Candida albicans) biofilm [22] and Cryptococcal biofilm [27] formation, and showed activity against Propionibacterium acnes biofilm [28].

The aim of this paper was to evaluate the influence of TZD-based azolidine and chlorophenyl thiosemicarbazone hybrids against both planktonic and biofilm-forming Haemophilus spp. cells. According to our knowledge, it is the first study about the effect of tested compounds against these fastidious bacteria with very specific growth requirements.

\section{Results and Discussion}

\subsection{Chemistry}

The objects of the present research were two series of previously obtained TZD-based hybrids [19,20]. The first group of compounds was a series A (Table 1) that consisted of TZD-based azolidine hybrids. Substances of series A were characterized by two nitrogenous five-membered heterocyclic rings. Compounds of series A were obtained by three-step synthesis using (2,4-dioxothiazolidin-5-yl/ylidne)acetic acids as starting materials. Target TZD-based azolidine hybrids were synthesized by the reaction of (2,4-dioxothiazolidin-5-yl/ylidene)acetic acid chlorides with 5-(hydroxybenzylidene)azolidine derivatives. The second group of research compounds was a series B (Table 2) that consisted of TZD-based chlorophenylthiosemicarbazone hybrids. Compounds of series B were obtained also by a three-step procedure, starting with appropriate (2,4-dioxothiazolidin-5-yl/ylidene)acetic acids and connection with the chlorophenylthiosemicarbazide fragment by the reaction of condensation in the last step of the synthesis.

Table 1. Thiazolidine-2,4-dionebased azolidine hybrids (series A) symbols and structure.

\begin{tabular}{|c|c|c|c|c|c|}
\hline & & & & & 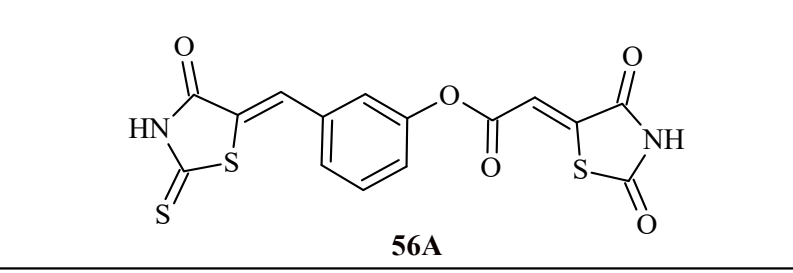 \\
\hline Compound $^{1}$ & z & $x$ & $\mathbf{R}$ & $\int$ & Compound Name \\
\hline $34 \mathrm{~A}$ & $\mathrm{O}$ & S & $\mathrm{Br}$ & single bond & $\begin{array}{l}\text { 2-Bromo-4-[(2,4-dioxo-1,3-thiazolidin-5-ylidene)methyl]phenyl } \\
\text { (2,4-dioxo-1,3-thiazolidin-5-yl)acetate }\end{array}$ \\
\hline $39 \mathrm{~A}$ & S & S & $\mathrm{OC}_{2} \mathrm{H}_{5}$ & single bond & $\begin{array}{l}\text { 2-Ethoxy-4-[(4-oxo-2-thioxo-1,3-thiazolidin-5-ylidene)methyl]phenyl } \\
\text { (2,4-dioxo-1,3-thiazolidin-5-yl)acetate }\end{array}$ \\
\hline $41 \mathrm{~A}$ & S & S & $\mathrm{Br}$ & single bond & $\begin{array}{l}\text { 2-Bromo-4-[(4-oxo-2-thioxo-1,3-thiazolidin-5-ylidene)methyl]phenyl } \\
\text { (2,4-dioxo-1,3-thiazolidin-5-yl)acetate }\end{array}$ \\
\hline $47 \mathrm{~A}$ & S & $\mathrm{NH}$ & $\mathrm{Br}$ & single bond & $\begin{array}{l}\text { 2-Bromo-4-[(5-oxo-2-thioxoimidazolidin-4-ylidene)methyl]phenyl } \\
\text { (2,4-dioxo-1,3-thiazolidin-5-yl)acetate }\end{array}$ \\
\hline $51 \mathrm{~A}$ & $\mathrm{O}$ & S & $\mathrm{OCH}_{3}$ & double bond & $\begin{array}{l}\text { 4-[(2,4-Dioxo-1,3-thiazolidin-5-ylidene)methyl]-2-methoxyphenyl } \\
\text { (2,4-dioxo-1,3-thiazolidin-5-ylidene)acetate }\end{array}$ \\
\hline $52 \mathrm{~A}$ & $\mathrm{O}$ & S & $\mathrm{OC}_{2} \mathrm{H}_{5}$ & double bond & $\begin{array}{l}\text { 4-[(2,4-Dioxo-1,3-thiazolidin-5-ylidene)methyl]-2-ethoxyphenyl } \\
\text { (2,4-dioxo-1,3-thiazolidin-5-ylidene)acetate }\end{array}$ \\
\hline
\end{tabular}


Table 1. Cont.

\begin{tabular}{cccccc}
\hline Compound ${ }^{1}$ & $\mathbf{Z}$ & $\mathbf{X}$ & $\mathbf{R}$ & $\mathrm{S}$ & \multicolumn{1}{c}{ Compound Name } \\
\hline $\mathbf{5 4 A}$ & $\mathrm{O}$ & $\mathrm{S}$ & $\mathrm{Br}$ & double bond & $\begin{array}{l}\text { 2-Bromo-4-[(2,4-dioxo-1,3-thiazolidin-5-ylidene)methyl]phenyl } \\
\text { (2,4-dioxo-1,3-thiazolidin-5-ylidene)acetate }\end{array}$ \\
\hline $\mathbf{5 6 A}$ & - & - & - & - & $\begin{array}{l}\text { 3-[(4-Oxo-2-thioxo-1,3-thiazolidin-5-ylidene)methyl]phenyl } \\
\text { (2,4-dioxo-1,3-thiazolidin-5-ylidene)acetate }\end{array}$ \\
\hline $\mathbf{5 7 A}$ & $\mathrm{S}$ & $\mathrm{S}$ & $\mathrm{H}$ & double bond & $\begin{array}{l}\text { 4-[(4-Oxo-2-thioxo-1,3-thiazolidin-5-ylidene)methyl]phenyl } \\
\text { (2,4-dioxo-1,3-thiazolidin-5-ylidene)acetate }\end{array}$ \\
\hline $\mathbf{5 8 A}$ & $\mathrm{S}$ & $\mathrm{S}$ & $\mathrm{OCH}_{3}$ & double bond & $\begin{array}{l}\text { 2-Methoxy-4-[(4-oxo-2-thioxo-1,3-thiazolidin-5-ylidene)methyl]phenyl } \\
\text { (2,4-dioxo-1,3-thiazolidin-5-ylidene)acetate }\end{array}$ \\
\hline $\mathbf{5 9 A}$ & $\mathrm{S}$ & $\mathrm{S}$ & $\mathrm{OC}_{2} \mathrm{H}_{5}$ & double bond & $\begin{array}{l}\text { 2-Ethoxy-4-[(4-oxo-2-thioxo-1,3-thiazolidin-5-ylidene)methyl]phenyl } \\
\text { (2,4-dioxo-1,3-thiazolidin-5-ylidene)acetate }\end{array}$ \\
\hline $\mathbf{6 0 A}$ & $\mathrm{S}$ & $\mathrm{S}$ & $\mathrm{Cl}$ & double bond & $\begin{array}{l}\text { 2-Chloro-4-[(4-oxo-2-thioxo-1,3-thiazolidin-5-ylidene)methyl]phenyl } \\
\text { (2,4-dioxo-1,3-thiazolidin-5-ylidene)acetate }\end{array}$ \\
\hline $\mathbf{6 4 A}$ & $\mathrm{S}$ & $\mathrm{NH}$ & $\mathrm{OC}_{2} \mathrm{H}_{5}$ & double bond & $\begin{array}{l}\text { 2-Ethoxy-4-[(5-oxo-2-thioxoimidazolidin-4-ylidene)methyl]phenyl } \\
\text { (2,4-dioxo-1,3-thiazolidin-5-ylidene)acetate }\end{array}$ \\
\hline
\end{tabular}

${ }^{1}$ Number of compounds were adapted from [19]. A-TZD-based azolidine hybrids.

Table 2. TZD-based chlorophenylthiosemicarbazone hybrids (series B) symbols and structure.

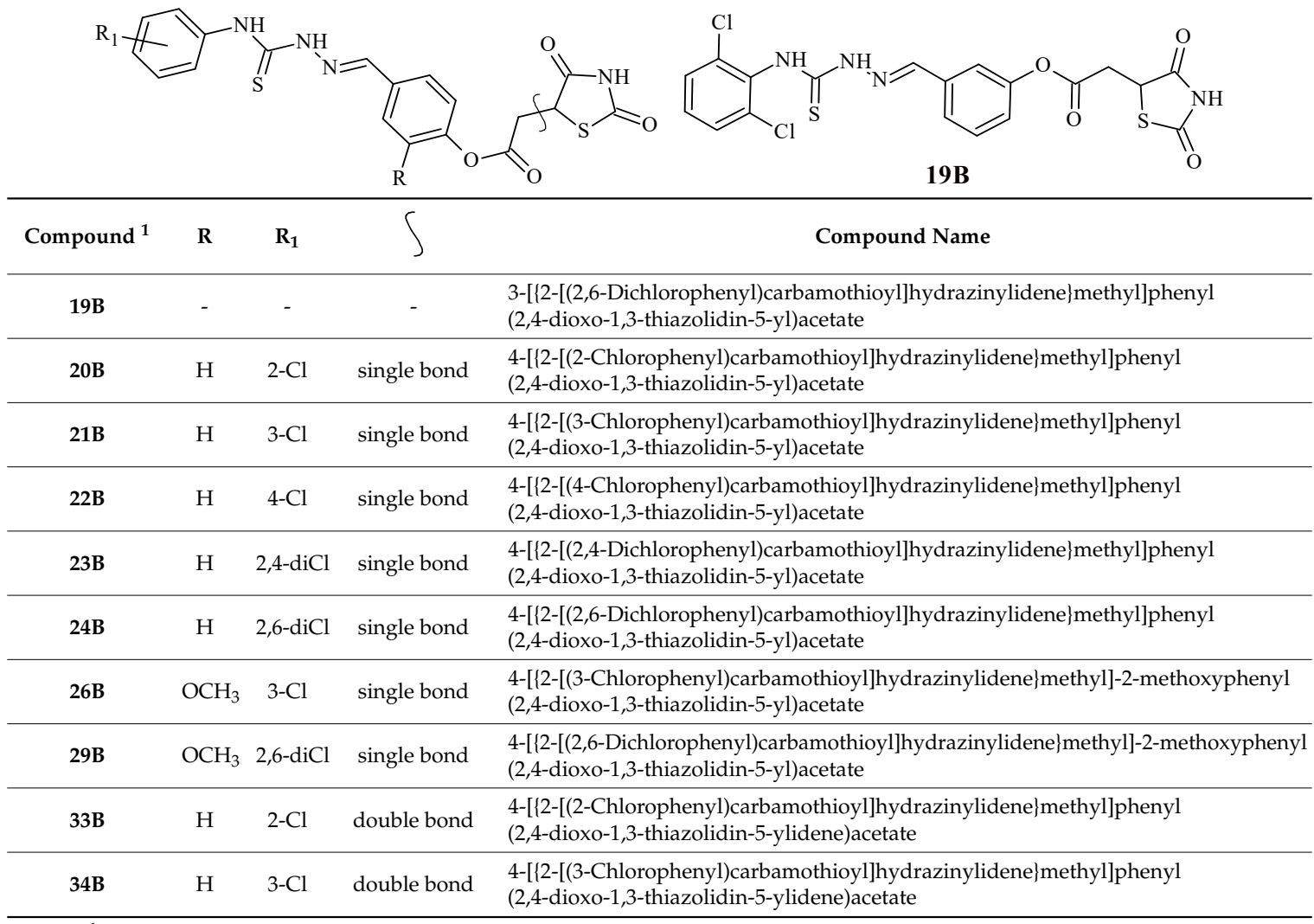

${ }^{1}$ Number of compounds were adapted from [20]. B-TZD-based chlorophenyl thiosemicarbazone hybrids.

\subsection{Activity Assay against Planktonic and Biofilm-Forming Cells}

The in vitro activity of the tested compounds against planktonic and biofilm-forming cells of reference and clinical isolates of Haemophilus spp. were evaluated by using the broth microdilution method. Among the 62 evaluated compounds, of TZD-based hybrids consisting of series A and B, 39 compounds were inactive against both planktonic and biofilm-forming cells of Haemophilus spp. in a concentration more than $1000 \mathrm{mg} / \mathrm{L}$. Three compounds had a very low inhibitory effect $(\mathrm{MIC}=500-1000 \mathrm{mg} / \mathrm{L})$ on the growth of planktonic and biofilm-forming cells of the tested bacteria. The other twenty compounds (twelve of series A and eight of series B) had a moderate effect on the 
growth, with MICs ranging from 31.25 to $250 \mathrm{mg} / \mathrm{L}$, and the biofilm formation, with MBICs ranging from 62.5 to $250 \mathrm{mg} / \mathrm{L}$.

Compounds 34A, 41A, 56A, and 60A showed activity at MIC value of $125 \mathrm{mg} / \mathrm{L}$ against reference strains and planktonic cells of Haemophilus spp. The activity of these compounds against biofilm-forming cells was at MBIC $=250 \mathrm{mg} / \mathrm{L}$. Substances $54 \mathrm{~A}$ and 57A showed activity with MIC $=62.5-125 \mathrm{mg} / \mathrm{L}$ against planktonic cells of reference strains. The activity of the $54 \mathrm{~A}$ compound against biofilm-forming cells was with MBIC value of $250 \mathrm{mg} / \mathrm{L}$ and for 57A with MBIC value of $1000 \mathrm{mg} / \mathrm{L}$. The activity of compounds of series A against biofilm-forming cells was highest for the clinical isolate of $H$. parainfluenzae 201. The compounds 39A, 52A, 54A, 56A, 57A, 59A, and $64 \mathrm{~A}$ showed this activity at MBIC $=125 \mathrm{mg} / \mathrm{L}$. This value was two-fold lower than for reference compound gentamycin. Compound 47A showed activity against $H$. parainfluenzae 201 biofilm-formation at $62.5 \mathrm{mg} / \mathrm{L}$, and it had very low activity against other Haemophilus spp. Worth

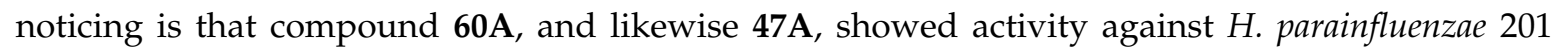
growth in biofilm at $62.5 \mathrm{mg} / \mathrm{L}$. Moreover, compounds 47A and 60A showed four-fold better activity against $H$. parainfluenzae 201 biofilm formation than gentamycin, and comparable activity with reference compound cefuroxime. Compound 60A had the best activity against both planktonic and biofilm-forming cells of Haemophilus spp. amongst evaluated compounds of series A.

All compounds of series A with moderate inhibitory antibacterial effect had, in its structure, an electron withdrawing group ( $\mathrm{Br}$ or $\mathrm{Cl}$ ) (compounds 34A, 41A, 47A, 54A and 60A) in the 2 position of the phenyl ring or were without substituent in this position (compounds 57A and its meta isomer 56A). Introducing an electron donating group (methoxy and ethoxy group) into the structure significantly decreased activity (compounds 39A, 51A, 52A, 58A and 59A). The type of azolidine heterocycle attached to the benzylidene fragment did not have a major impact on the activity, as well as the presence of the double bond in position 5 of the TZD system.

Compounds of series B, generally, showed very low activity against planktonic and biofilm-forming cells, for the three reference species and the three clinical isolates of haemophili. It is worth paying attention to the clinical $H$. parainfluenzae 201 isolate. Against this strain, the most active were compounds of series B (19B, 21B, 23B, 24B, 26B, and 29B)-with MIC value of $100-125 \mathrm{mg} / \mathrm{L}$. The 22B compound was active against planktonic cells of the H. parainfluenzae 201 isolate, with MIC $=31.25 \mathrm{mg} / \mathrm{L}$.

To determine the power of the tested compounds (series A and series B) as agents with anti-biofilm activity, they were compared with the activity against planktonic cells on the basis of the MBIC/MIC ratio. The results, included in Table 3, showed that the MBIC/MIC ratio ranged 1-8 in the case of H. parainfluenzae ATCC 33392, 1-16 in the case of H. parainfluenzae ATCC 51505, and 1-4 in the case of $H$. influenzae ATCC 10211. In the case of clinical isolate H. parainfluenzae 201, the MBIC/MIC ratio ranged within 0.0625-0.5 for compounds of series A, and within 0.5-32 for derivatives of series $\mathrm{B}$. As shown by the MBIC/MIC ratio equal $<1$ in some cases, the activity against biofilm-forming cells was higher compared to the activity against planktonic cells of the same species. 
Table 3. The antibacterial activity of TZD-based azolidine and chlorophenyl thiosemicarbazone hybrids against planktonic and biofilm-forming cells, of reference strains and clinical isolates of Haemophilus spp., in vitro under stationary conditions.

\begin{tabular}{|c|c|c|c|c|c|c|c|c|c|c|c|c|c|c|c|c|c|c|c|c|c|}
\hline \multirow[b]{2}{*}{ Compound } & \multicolumn{9}{|c|}{ Reference Species } & \multicolumn{12}{|c|}{ Clinical Isolates } \\
\hline & \multicolumn{3}{|c|}{$\begin{array}{l}\text { Haemophilus parainfluenzae } \\
\text { ATCC } 33392\end{array}$} & \multicolumn{3}{|c|}{$\begin{array}{l}\text { Haemophilus parainfluenzae } \\
\text { ATCC } 51505\end{array}$} & \multicolumn{3}{|c|}{$\begin{array}{l}\text { Haemophilus influenzae } \\
\text { ATCC } 10211\end{array}$} & \multicolumn{3}{|c|}{$\begin{array}{c}\text { Haemophilus parainfluenzae } \\
128\end{array}$} & \multicolumn{3}{|c|}{$\begin{array}{l}\text { Haemophilus parainfluenzae } \\
\qquad 134\end{array}$} & \multicolumn{3}{|c|}{$\begin{array}{l}\text { Haemophilus parainfluenzae } \\
\qquad 201\end{array}$} & \multicolumn{3}{|c|}{$\begin{array}{l}\text { Haemophilus parainfluenzae } \\
206\end{array}$} \\
\hline \multicolumn{22}{|c|}{ Antibacterial Activity (mg/L) } \\
\hline & MIC & MBIC & $\begin{array}{l}\text { MBIC/ } \\
\text { MIC }\end{array}$ & MIC & MBIC & $\begin{array}{l}\text { MBIC/ } \\
\text { MIC }\end{array}$ & MIC & MBIC & $\begin{array}{l}\text { MBIC/ } \\
\text { MIC }\end{array}$ & MIC & MBIC & $\begin{array}{l}\text { MBIC/ } \\
\text { MIC }\end{array}$ & MIC & MBIC & $\begin{array}{l}\text { MBIC/ } \\
\text { MIC }\end{array}$ & MIC & MBIC & $\begin{array}{l}\text { MBIC/ } \\
\text { MIC }\end{array}$ & MIC & MBIC & $\begin{array}{l}\text { MBIC/ } \\
\text { MIC }\end{array}$ \\
\hline $34 \mathrm{~A}$ & 125 & 250 & 2 & 125 & 250 & 2 & 125 & 250 & 2 & $>1000$ & $>1000$ & - & $>1000$ & $>1000$ & - & 1000 & 250 & 0.25 & $>1000$ & 1000 & - \\
\hline $39 \mathrm{~A}$ & 500 & $>1000$ & - & 500 & 1000 & 2 & 500 & $>1000$ & - & $>1000$ & $>1000$ & - & $>1000$ & 1000 & - & 250 & 125 & & $>1000$ & 1000 & - \\
\hline $41 \mathrm{~A}$ & 125 & 250 & 2 & 125 & 250 & 2 & 125 & 250 & 2 & $>1000$ & 500 & - & $>1000$ & $>1000$ & 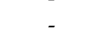 & 500 & 250 & 0.5 & $>1000$ & $>1000$ & - \\
\hline $47 \mathrm{~A}$ & 500 & 1000 & 2 & 500 & 1000 & 2 & 500 & 1000 & 2 & $>1000$ & 500 & - & $>1000$ & 1000 & - & 1000 & 62.5 & 0.0625 & $>1000$ & 1000 & - \\
\hline $51 \mathrm{~A}$ & 500 & 500 & 1 & 500 & 500 & 1 & 500 & 500 & 1 & $>1000$ & 500 & - & $>1000$ & 1000 & - & 1000 & $>1000$ & - & $>1000$ & 500 & - \\
\hline $52 \mathrm{~A}$ & 500 & 1000 & 2 & 500 & 1000 & 2 & 500 & 1000 & 2 & $>1000$ & 1000 & - & $>1000$ & 500 & - & 250 & 125 & 0.5 & $>1000$ & 500 & - \\
\hline $54 \mathrm{~A}$ & 125 & 250 & 2 & 125 & 250 & 2 & 62.5 & 250 & 4 & $>1000$ & $>1000$ & 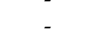 & $>1000$ & $>1000$ & 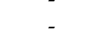 & 500 & 125 & 0.25 & $>1000$ & 1000 & 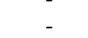 \\
\hline $56 \mathrm{~A}$ & 125 & 250 & 2 & 125 & 250 & 2 & 125 & 250 & 2 & $>1000$ & $>1000$ & - & $>1000$ & 250 & - & 1000 & 125 & 0.125 & $>1000$ & 250 & - \\
\hline $57 \mathrm{~A}$ & 125 & 1000 & 8 & 62.5 & 1000 & 16 & 500 & $>1000$ & - & $>1000$ & $>1000$ & - & $>1000$ & $>1000$ & - & 1000 & 125 & 0.125 & $>1000$ & 250 & - \\
\hline $58 \mathrm{~A}$ & 250 & 1000 & 4 & 250 & 1000 & 4 & 250 & 1000 & 4 & $>1000$ & $>1000$ & - & $>1000$ & 1000 & - & 500 & $>1000$ & 0.120 & $>1000$ & 1000 & - \\
\hline $59 \mathrm{~A}$ & 500 & 500 & 1 & 500 & 500 & 1 & 500 & 500 & 1 & $>1000$ & $>1000$ & - & $>1000$ & $>1000$ & - & 1000 & 125 & 0.125 & 1000 & $>1000$ & - \\
\hline $60 \mathrm{~A}$ & 125 & 250 & 2 & 125 & 250 & 2 & 125 & 250 & 2 & $>1000$ & $>1000$ & - & $>1000$ & $>1000$ & - & 1000 & 62.5 & 0.0625 & $>1000$ & 1000 & - \\
\hline $64 \mathrm{~A}$ & 250 & $>1000$ & - & 1000 & $>1000$ & 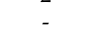 & 1000 & $>1000$ & 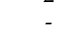 & $>1000$ & 1000 & - & $>1000$ & $>1000$ & - & 1000 & 125 & 0.125 & 250 & $>1000$ & - \\
\hline 19B & $>1000$ & 500 & - & $>1000$ & $>1000$ & - & $>1000$ & 500 & - & $>1000$ & $>1000$ & - & $>1000$ & 500 & - & 125 & 125 & 1 & $>1000$ & 1000 & - \\
\hline $20 \mathrm{~B}$ & $>1000$ & $>1000$ & - & $>1000$ & $>1000$ & - & $>1000$ & $>1000$ & - & $>1000$ & $>1000$ & - & $>1000$ & 1000 & - & 500 & 1000 & 2 & $>1000$ & 1000 & - \\
\hline $21 B$ & $>1000$ & $>1000$ & - & $>1000$ & $>1000$ & - & $>1000$ & $>1000$ & - & $>1000$ & $>1000$ & - & $>1000$ & 1000 & - & 125 & 1000 & 8 & $>1000$ & 1000 & - \\
\hline $22 \mathrm{~B}$ & $>1000$ & $>1000$ & 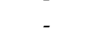 & $>1000$ & $>1000$ & 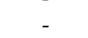 & $>1000$ & $>1000$ & 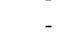 & $>1000$ & $>1000$ & 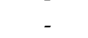 & $>1000$ & 50 & 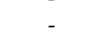 & 31.25 & 1000 & $\begin{array}{l}0 \\
32\end{array}$ & $>1000$ & 1000 & 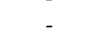 \\
\hline 23B & 1000 & $>1000$ & - & $>1000$ & $>1000$ & - & $>1000$ & $>1000$ & - & 1000 & 1000 & 1 & $>1000$ & 1000 & - & 125 & 1000 & 8 & $>1000$ & 1000 & - \\
\hline $24 \mathrm{~B}$ & $>1000$ & $>1000$ & - & $>1000$ & $>1000$ & - & $>1000$ & $>1000$ & - & $>1000$ & $>1000$ & - & $>1000$ & $>1000$ & - & 125 & 1000 & 8 & $>1000$ & 1000 & - \\
\hline $26 \mathrm{~B}$ & $>1000$ & $>1000$ & - & $>1000$ & $>1000$ & - & $>1000$ & $>1000$ & - & $>1000$ & $>1000$ & - & $>1000$ & 1000 & - & 100 & 1000 & 10 & $>1000$ & 1000 & - \\
\hline $\begin{array}{l}29 \mathrm{~B} \\
29 \mathrm{~B}\end{array}$ & $>1000$ & $>1000$ & - & $>1000$ & $>1000$ & - & $>1000$ & $>1000$ & - & $>1000$ & $>1000$ & 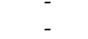 & $>1000$ & 1000 & - & $\begin{array}{l}100 \\
100\end{array}$ & 500 & 5 & $>1000$ & 1000 & 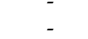 \\
\hline $33 B$ & $>1000$ & $>1000$ & - & $>1000$ & $>1000$ & - & $>1000$ & $>1000$ & - & $>1000$ & $>1000$ & - & $>1000$ & $>1000$ & - & 1000 & 1000 & 1 & $>1000$ & 1000 & - \\
\hline $34 \mathrm{~B}$ & 250 & $>1000$ & - & 500 & $>1000$ & - & 500 & $>1000$ & - & $>1000$ & $>1000$ & - & $>1000$ & $>1000$ & - & 500 & 250 & 0.5 & $>1000$ & 1000 & - \\
\hline $\mathrm{Ge}$ & 250 & 250 & 1 & 1000 & 250 & 0.25 & 500 & 250 & 0.5 & 1000 & 1000 & 1 & 1000 & 500 & 0.5 & 500 & 250 & 0.5 & 1000 & 500 & 0.5 \\
\hline Cef & 125 & 125 & 1 & 500 & 125 & 0.25 & 125 & 62.5 & 0.5 & 500 & 125 & 0.25 & 500 & 62.5 & 0.13 & 250 & 62.5 & 0.25 & 250 & 125 & 0.5 \\
\hline
\end{tabular}

MIC—-minimal inhibitory concentration, MBIC—minimal biofilm inhibitory concentration, MBIC/MIC—minimal biofilm inhibitory concentration/minimal inhibitory concentration ratio, Ge—gentamycin, Cef—cefuroxime, "-"—not determined. 
The most anti-adhesive properties of tested compounds 54A, 56A, 59A, and 60A with potential antibiofilm activity $(\mathrm{MBIC}=62.5-250 \mathrm{mg} / \mathrm{L})$ against reference species of $H$. parainfluenzae and H. influenzae were detected. As was shown on the $54 \mathrm{~A}$ compound example (Figure 1), the inhibitory effect against the first step of biofilm formation of tested compounds was dependent on both the compound and their concentration. The anti-adhesive properties were reversible during long-term incubation of bacteria in the presence of lower concentrations of compounds. After $24 \mathrm{~h}$ of incubation, biofilm was formed independently to the initial inhibition of the adhesion of bacteria to the polystyrene surface.

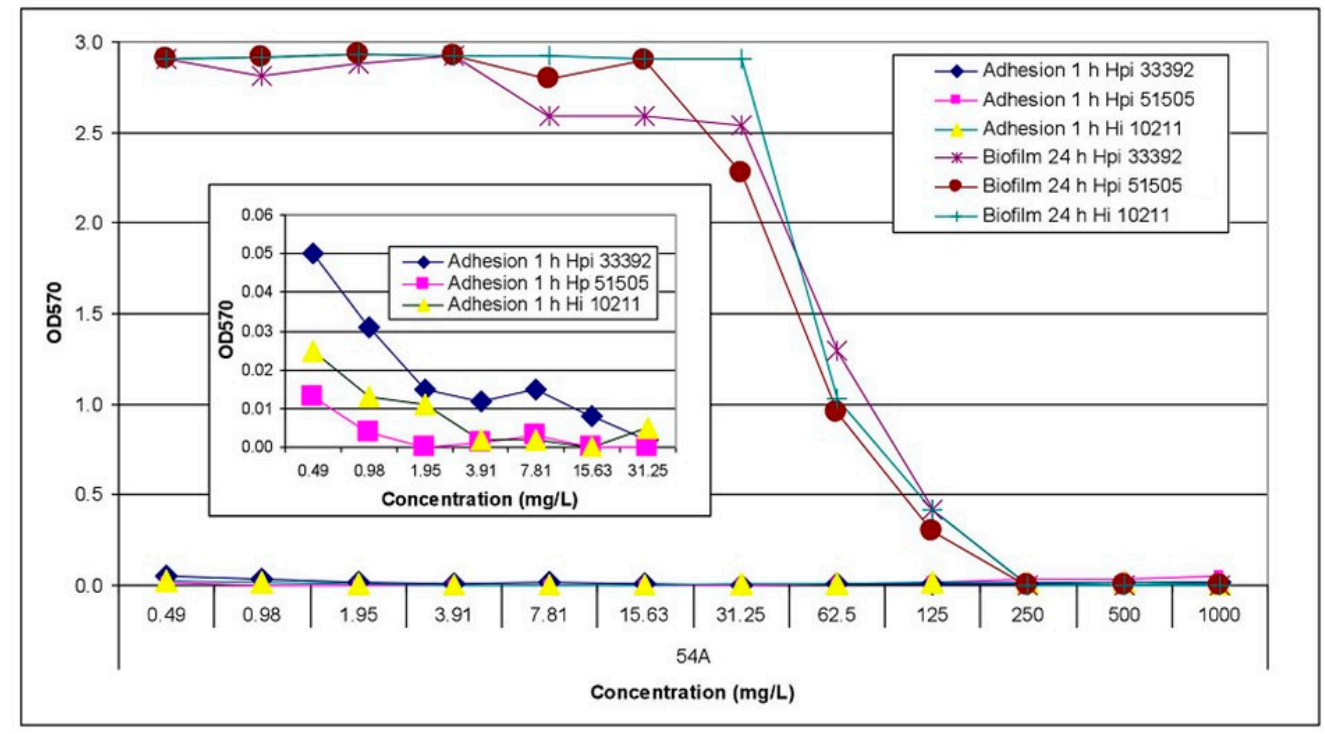

Figure 1. Anti-adhesive and antibiofilm activity of compound 54A against reference haemophili species, assessed on the basis of $\mathrm{OD}_{570}$ values. Hpi-Haemophilus parainfluenzae, Hi-Haemophilus influenzae.

Among the compounds (54A, 56A, 59A, and 60A) with the most anti-adhesive properties, all substances were derivatives of (2,4-dioxothiazolidin-5-ylidene)acetic acid with a double bond in the 5 position of the TZD ring, and mainly contained rhodanine ring (compounds 56A, 59A and 60A) in its structure. The substituent in the 2 position of the phenyl ring did not play a significant role in the anti-adhesive properties; additionally, the isomerization in the phenyl ring (meta isomer compound 56A) seemed to be negligible.

It is known that adhesion is the key stage of biofilm formation and microbial colonization, and it is an essential element of microbial virulence. The ability of microorganisms to adhere to eukaryotic cells is a pathogenic factor that is considered to be the first stage of infection. It depends, to a large extent, on the characteristics of prokaryotic cells, such as the production of extracellular factors (e.g., mucus) and the specific features of the surfaces (e.g., their structure, hydrophobicity, and presence of receptors). They can affect the adhesive properties of microorganisms to abiotic and biotic surfaces and the possibility of biofilm formation [29]. Detected MBIC values were often lower compared to the MICs after $24 \mathrm{~h}$ of culture (Table 3). Additionally, the adhesion of tested bacteria was inhibited at lower concentrations of the tested compounds. These values indicate that the test substances and both the antibiotics inhibited the biofilm formation by the cells of the tested strains, at concentrations that did not affect their growth. This suggests that in the case of Haemophilus spp., the activity of these compounds was related to their effect on the initial phases of biofilm formation, as well as adhesion properties and adherence of cells to the solid surface.Found that cefuroxime, at sub-inhibitory concentrations below $50 \%$ of MIC, inhibited the adhesion of various $H$. influenzae strains to cheek epithelial cells [30]. The influence of sub-inhibitory concentrations of various antimicrobial substances on biofilm formation in the early stages of its formation was demonstrated by many authors (e.g., [31]). Incubation of Escherichia coli with sub-inhibitory concentrations of ciprofloxacin 
blocked bacterial adhesion [32]. The use of other antibiotics (e.g., piperacillin with tazobactam) at a concentration of $1 / 2$ MIC caused inhibition of Pseudomonas aeruginosa biofilm formation on polystyrene plates [33]. This phenomenon was caused by the reduction of the cell adhesion capacity as a result of morphological changes, such as cell elongation. Additionally, co-trimoxazole caused the greatest inhibition of adhesion at $1 / 2$ MIC of E. coli strain, when compared with the controls, followed by ceftazidime [34].

The biofilm structure, formed by bacteria and fungi, is an important problem related to the use of antimicrobials [35]. Several approaches have been studied to prevent the adhesion to various surfaces (natural or synthetic) and of microorganisms growing in biofilm. The ability of newly synthesized compounds to affect microbial adherence and biofilm formation may be an important criterion in selecting the ones, for the design of the substances, with the improved antimicrobial activity. It is known that low (sub-MICs) concentrations of antimicrobials do not kill bacteria, but they are capable of changing their biochemical and structural properties. The final effect is a reduction of bacterial pathogenicity by compounds' interference with the important aspects of bacterial properties, including adherence, fimbriation, or motility.

\section{Materials and Methods}

\subsection{Chemistry}

In this work, the following TZD-based azolidine and chlorophenylthiosemicarbazone hydrids were used [19,20]. TZD-based azolidine hybrids seria consisted of 38 compounds (series A). But TZD-based chlorophenylthiosemicarbazone hybrids seria consisted of 24 compounds (serie B). The physicochemical and spectral characteristic of the compounds of series A and B, as well as the rationale for the chemical combination of the above mentioned structures in one compound, was described in previously published papers $[19,20]$.

\subsection{Bacterial Strains}

The haemophili reference species from American Type Culture Collection (ATCC)—H. influenzae ATCC 10211, H. parainfluenzae ATCC 33392, and H. parainfluenzae ATCC 51505 were included. Besides, four clinical isolates of $H$. parainfluenzae from the collection of the Department of Pharmaceutical Microbiology with Laboratory for Microbiological Diagnostics of Medical University of Lublin were used. Bacterial strains were suspended in fresh TSB + HTMS medium and standardized with $\mathrm{OD}_{600}$ equivalent to the $0.5 \mathrm{McF}$ arland standard $\left(\mathrm{OD}_{600}=0.08 \pm 0.02\right)$, using the microplate reader ELx800 (BioTek, Instruments, Winooski, VT, USA). For each measurement, the bacterial suspensions were prepared independently.

\subsection{Determination of the Minimal Inhibitory Concentration (MIC) of Tested TZD-Based Azolidine and Chlorophenyl Thiosemicarbazone Hybrids}

Antibacterial activity of TZD-based azolidine hybrids and TZD-based chlorophenylthiosemicarbazone hybrids, as well as of reference agents against planktonic cells of bacteria, was screened with Haemophilus spp. reference strains and clinical isolates by the broth microdilution method, using 96-well polystyrene microplates (96F-Well Microplates, Thermo Scientific ${ }^{\mathrm{TM}}$ Nunc $^{\mathrm{TM}}$ Brand Product, Roskilde, Denmark). The medium was prepared from TSB (trypticase soy broth; Biocorp, Warsaw, Poland) and 0.4\% HTMS (Haemophilus test medium supplemented with growth factors for haemophili-25 mg/L of NAD and $15 \mathrm{mg} / \mathrm{L}$ of hematin, Oxoid, UK) and marked as TSB + HTMS. Stock solutions of TZD-based hybrids at a concentration of $50 \mathrm{mg} / \mathrm{mL}$ in dimethyl sulfoxide (DMSO, Sigma Aldrich, St. Louis, MO, USA) were prepared and diluted in TSB + HTMS medium, in the range of concentration depending on the experiment. The activity of the compounds tested against planktonic cells was determined as the MIC, defined as the lowest concentration of the antimicrobial agents that inhibits visible growth of bacteria, according 
to the EUCAST procedure [36] with some modifications [37]. The medium with bacteria and without the tested compounds added served as a growth control. The wells with a two-fold dilution of the tested compounds added to TSB + HTMS broth and without bacterial suspension served as compound control (negative control) and with antimicrobials (gentamicin and cefuroxime) as reference agents (positive control). The wells with only TSB + HTMS broth and without bacterial suspension was a medium sterility control. All controls were incubated under the same conditions in three replications for a blank value. Each measurement was performed in triplicate, and both positive and negative controls were kept. During the experiments, $198 \mu \mathrm{L}$ of TSB + HTMS medium, with and without a series of two-fold dilutions of the tested compounds or reference compounds, were inoculated with $2 \mu \mathrm{L}$ of the standardized microbial suspension (total volume per each well-200 $\mu \mathrm{L} /$ well), and then incubated for $24 \mathrm{~h}$ at $35{ }^{\circ} \mathrm{C}$ in the presence of about $5 \% \mathrm{CO}_{2}$. Absorbance was measured as an $\mathrm{OD}_{570}$ using a microplate reader. Each measurement was made in triplicate.

\subsection{Determination of the Minimal Biofilm Inhibitory Concentration (MBIC) of Tested TZD-Based Azolidine and Chlorophenyl Thiosemicarbazone Hybrids}

In order to assay the effect on Haemophilus spp. of biofilm formation, the method based on staining with $0.1 \%$ crystal violet, as described earlier [38], was used. The activity of the tested compound against biofilm-forming cells was determined on the basis of MBIC (minimal biofilm inhibitory concentration), defined as the lowest concentration of the tested compound at which the biofilm formation was inhibited [39], and in the concentration at which bacterial growth was observed [40]. After overnight incubation of bacterial isolates under microaerophilic atmosphere and conditions described above, the medium above the culture was decanted and then the plates were washed extensively several times with distilled water to remove nonadherent or loosely adherent cells, dried in inverted position, and stained with $200 \mu \mathrm{L}$ of $0.1 \%$ crystal violet. The plates were left for $15 \mathrm{~min}$ at room temperature to stain the cells, then washed extensively under distilled water to remove unbound dye. Next, in order to elicit a response to each of the wells, $200 \mu \mathrm{L}$ of ethanol alcohol was added and the plates were left at room temperature for $15 \mathrm{~min}$ to solubilize the dye into the alcohol. The $\mathrm{OD}_{570}$ of the alcohol-dye solution in each well was read by using a microplate reader (BioTek ELx800). The blank control wells, without or with two-fold dilution of the tested compounds and reference agents added to the same broth but without bacterial suspension, were incubated under the same conditions. OD $_{570}$ values read in these wells were the ODc values, being the reference point for determining the MBIC value.

\subsection{Determination of the Anti-Adhesive Properties of Tested TZD-Based Azolidine and Chlorophenylthiosemicarbazone Hybrids}

The anti-adhesive properties of tested compounds were assessed after $1 \mathrm{~h}$ incubation in the conditions and by a method such as the biofilm was done, but after the incubation time of $1 \mathrm{~h}$. Besides the much shorter time of incubation, the assay was carried out according to the biofilm detection procedure (as stated above). After $1 \mathrm{~h}$ of incubation, the cultures from microplates were removed, the wells were rinsed and, after drying, stained with $0.1 \%$ crystal violet for $10 \mathrm{~min}$. After washing off the excess dye, microwells were poured for $15 \mathrm{~min}$ with ethanol. It was very important to determine the $\mathrm{OD}_{570}$ values for the same substances without cells. Absorbance values were obtained using a $570 \mathrm{~nm}$ wavelength spectrometer $\left(\mathrm{OD}_{570}\right)$.

\section{Conclusions}

The influence of TZD-based azolidine (series A) and chlorophenylthiosemicarbazone (series B) hybrids against both planktonic and biofilm-forming Haemophilus spp. cells was evaluated. In addition, anti-adhesive properties of these compounds were examined. Among the tested compounds, twenty derivatives possessed moderate effect on the growth, with MICs ranging from 31.25 to $250 \mathrm{mg} / \mathrm{L}$, and the biofilm formation, with MBICs ranging from 62.5 to $250 \mathrm{mg} / \mathrm{L}$. The compounds 54A, 56A, 59A, and 60A, with potential antibiofilm activity against reference species of $H$. parainfluenzae and 
H. influenzae, exhibited good anti-adhesive properties. The observed anti-adhesive properties of the tested compounds were reversible during long-term incubation in lower concentration of compounds.

Author Contributions: Conceptualization, N.T. and U.K.; methodology, U.K. and S.A.; formal analysis, N.T. and U.K.; investigation, N.T., S.A., and U.K.; resources, N.T. and U.K.; data curation, N.T., A.P., S.A., and U.K.; writing—original draft preparation, N.T. and S.A.; writing—review and editing, U.K., A.P., and M.W.; visualization, N.T. and U.K.; supervision, N.T., U.K., and M.W.

Funding: This research was funded by Medical University of Lublin (DS 15).

Conflicts of Interest: The authors declare no conflicts of interest.

\section{References}

1. Kaplan, J.B. Biofilm dispersal: Mechanisms, clinical implications, and potential therapeutic uses. J. Dent. Res. 2010, 89, 205-219. [CrossRef] [PubMed]

2. Chernysh, S.; Gordya, N.; Tulin, D.; Yakovlev, A. Biofilm infections between Scylla and Charybdis: Interplay of host antimicrobial peptides and antibiotics. Infect. Drug Resist. 2018, 11, 501-514. [CrossRef] [PubMed]

3. Jamal, M.; Ahmad, W.; Andleeb, S.; Jalil, F.; Imran, M.; Nawaz, M.A.; Hussain, T.; Ali, M.; Rafiq, M.; Kamil, M.A. Baterial biofilm and associated infections. J. Chin. Med. Assoc. 2018, 81, 7-11. [CrossRef] [PubMed]

4. Dickson, R.P.; Huang, Y.J.; Martinez, F.J.; Huffnagle, G.B. The lung microbiome and viral-induced exacerbations of chronic obstructive pulmonary disease: New observations, novel approaches. Am. J. Respir. Crit. Care Med. 2013, 188, 1185-1186. [CrossRef]

5. Nørskov-Lauritsen, N. Classification, identification, and clinical significance of Haemophilus and Aggregatibacter species with host specificity for humans. Clin. Microbiol. Rev. 2014, 27, 214-240. [CrossRef] [PubMed]

6. Agrawal, A.; Murphy, T.F. Haemophilus influenzae infections in the H. influenzae type b conjugate vaccine era. J. Clin. Microbiol. 2011, 49, 3728-3732. [CrossRef] [PubMed]

7. Choi, D.; Thermidor, M.; Cunha, B.A. Haemophilus parainfluenzae mitral prosthetic valve endocarditis in an intravenous drug abuser. Heart Lung 2005, 34, 152-154. [CrossRef]

8. Mitchell, J.L.; Hill, S.L. Immune response to Haemophilus parainfluenzae in patients with chronic obstructive lung disease. Clin. Diagn. Lab. Immunol. 2000, 7, 25-30. [CrossRef] [PubMed]

9. Couturier, M.R.; Mehinovic, E.; Croft, A.C.; Fisher, M.A. Identification of HACEK clinical isolates by matrix-assisted laser desorption ionization-time of flight mass spectrometry. J. Clin. Microbiol. 2011, 49, 1104-1106. [CrossRef] [PubMed]

10. Ebbing, R.; Robertson, C.F.; Robinson, P.J. Haemophilus influenzae and Haemophilus parainfluenzae in cystic fibrosis: 15 year experience. J. Med. Microbiol. Diagn. 2015, 5. [CrossRef]

11. Kosikowska, U.; Rybojad, P.; Stępień-Pyśniak, D.; Żbikowska, A.; Malm, A. Changes in the prevalence and biofilm formation of Haemophilus influenzae and Haemophilus parainfluenzae from the respiratory microbiota of patients with sarcoidosis. BMC Infect. Dis. 2016, 16, 449. [CrossRef] [PubMed]

12. Kosikowska, U.; Korona-Głowniak, I.; Niedzielski, A.; Malm, A. Nasopharyngeal and adenoid colonization by Haemophilus influenzae and Haemophilus parainfluenzae in children undergoing adenoidectomy and the ability of bacterial isolates to biofilm production. Medicine (Baltimore) 2015, 94, e799. [CrossRef]

13. Lau, P.C.; Dutcher, J.R.; Beveridge, T.J.; Lam, J.S. Absolute quantitation of bacterial biofilm adhesion and viscoelasticity by microbead force spectroscopy. Biophys. J. 2009, 96, 2935-2948. [CrossRef]

14. Available online: https://www.cdc.gov/hi-disease/clinicians.html (accessed on 7 March 2019).

15. Tristram, S.; Jacobs, M.R.; Appelbaum, P.C. Antimicrobial resistance in Haemophilus influenzae. Clin. Microbiol. Rev. 2007, 20, 368-389. [CrossRef]

16. Abotsi, R.E.; Govinden, U.; Essack, S.Y. Mechanisms of antibiotic resistance in Haemophilus parainfluenzae. S. Afr. J. Infect. Dis. 2017, 32, 111-114. [CrossRef]

17. Jain, V.S.; Vora, D.K.; Ramaa, C.S. Thiazolidine-2,4-diones: Progress towards multifarious applications. Bioorg. Med. Chem. 2013, 21, 1599-1620. [CrossRef] [PubMed]

18. Asati, V.; Mahapatra, D.K.; Bharti, S.K. Thiazolidine2,4-diones as multi-targed scaffold in medicinal chemistry: Potential anticancer agents. Eur. J. Med. Chem. 2014, 87, 814-833. [CrossRef] 
19. Trotsko, N.; Kosikowska, U.; Paneth, A.; Wujec, M.; Malm, A. Synthesis and antibacterial activity of new (2,4-dioxothiazolidin-5-yl/ylidene)acetic acid derivatives with thiazolidine-2,4-dione, rhodanine and 2-thiohydantoin moieties. Saudi Pharm. J. 2018, 26, 568-577. [CrossRef] [PubMed]

20. Trotsko, N.; Kosikowska, U.; Paneth, A.; Plech, T.; Malm, A.; Wujec, M. Synthesis and antibacterial activity of new thiazolidine-2,4-dione-based chlorophenylthiosemicarbazone hybrids. Molecules 2018, $23,1023$. [CrossRef]

21. Shenderovich, J.; Feldman, M.; Kirmayer, D.; Al-Quntar, A.; Steinberg, D.; Lavy, E.; Friedman, M. Local sustained-release delivery systems of the antibiofilm agent thiazolidinedione- 8 for prevention of catheter-associated urinary tract infections. Int. J. Pharm. 2015, 485, 164-170. [CrossRef]

22. Feldman, M.; Al-Quntar, A.; Polacheck, I.; Friedman, M.; Steinberg, D. Therapeutic potential of thiazolidinedione-8 as an antibiofilm agent against Candida albicans. PLoS ONE 2014, 9, e93225. [CrossRef] [PubMed]

23. Feldman, M.; Shenderovich, J.; Al-Quntar, A.; Friedman, M.; Steinberg, D. Sustained Release of a Novel Anti-Quorum-Sensing Agent against Oral Fungal Biofilms. Antimicrob. Agents Chemother. 2015, 59, 2265-2272. [CrossRef] [PubMed]

24. Feldman, M.; Ginsburg, I.; Al-Quntar, A.; Steinberg, D. Thiazolidinedione-8 alters symbiotic relationship in C. albicans- S. mutans dual species biofilm. Front. Microbiol. 2016, 7, 140. [CrossRef] [PubMed]

25. Feldman, M.; Shenderovich, J.; Lavy, E.; Friedman, M.; Steinberg, D. A sustained-release membrane of thiazolidinedione-8: Effect on formation of a Candida/Bacteria mixed biofilm on hydroxyapatite in a continuous flow model. BioMed Res. Int. 2017, 2017, 3510124. [CrossRef] [PubMed]

26. Kagan, S.; Jabbour, A.; Sionov, E.; Alquntar, A.A.; Steinberg, D.; Srebnik, M.; Nir-Paz, R.; Weiss, A.; Polacheck, I. Anti-Candida albicans biofilm effect of novel heterocyclic compounds. J. Antimicrob. Chemother. 2014, 69, 416-427. [CrossRef]

27. Korem, M.; Kagan, S.; Polacheck, I. The effect of novel heterocyclic compounds on Cryptococcal biofilm. J. Fungi 2017, 3, 42. [CrossRef]

28. Brackman, G.; Forier, K.; Al Quntar, A.A.A.; De Canck, E.; Enk, C.D.; Srebnik, M.; Braeckmans, K.; Coenye, T. Thiazolidinedione derivatives as novel agents against Propionibacterium acnes biofilms. J. Appl. Microbiol. 2013, 116, 492-501. [CrossRef]

29. Coenye, T.; Nelis, H. In vitro and in vivo model systems to study microbial biofilm formation. J. Microbiol. Methods 2010, 83, 89-105. [CrossRef]

30. Jallat, C.; Darfeuille-Michaud, A.; Joly, B.; Cluzel, R. Inhibition of Haemophilus influenzae adherence to buccal epithelial cells by cefuroxime. Chemotherapy 1992, 38, 428-432. [CrossRef] [PubMed]

31. Starner, T.D.; Shrout, J.D.; Parsek, M.R.; Appelbaum, P.C.; Kim, G. Subinhibitory concentrations of azithromycin decrease nontypeable Haemophilus influenzae biofilm formation and Diminish established biofilms. Antimicrob. Agents Chemother. 2008, 52, 137-145. [CrossRef]

32. Wojnicz, D.; Jankowski, S. Effects of subinhibitory concentrations of amikacin and ciprofloxacin on the hydrophobicity and adherence to epithelial cells of uropathogenic Escherichia coli strains. Int. J. Antimicrob. Agents 2007, 29, 700-704. [CrossRef]

33. Fonseca, A.P.; Extremina, C.; Fonseca, A.F.; Sousa, J.C. Effect of subinhibitory concentration of piperacillin/tazobactam on Pseudomonas aeruginosa. J. Med. Microbiol. 2004, 53, 903-910. [CrossRef]

34. Vidya, K.C.; Mallya, P.S.; Rao, P.S. Inhibition of bacterial adhesion by subinhibitory concentrations of antibiotics. Indian J. Med. Microbiol. 2005, 23, 102-105.

35. Høiby, N.; Bjarnsholt, T.; Moser, C.; Bassi, G.L.; Coenye, T.; Donelli, G.; Hall-Stoodley, L.; Hola, V.; Imbert, C.; Kirketerp-Møller, K.; et al. ESCMID guidline for the diagnosis and biofilm infections 2014. Clin. Microbiol. Infect. 2015, 21 (Suppl. 1), S1-S25. [CrossRef]

36. European Committee for Antimicrobial Susceptibility Testing (EUCAST) of the European Society for Clinical Microbiology and Infectious Diseases (ESCMID). EUCAST Discussion Document E. Dis. 5.1: Determination of minimum inhibitory concentrations (MICs) of antibacterial agents by broth dilution. Clin. Microbiol. Infect. 2003, 9, 1-7.

37. Kosikowska, U.; Andrzejczuk, S.; Plech, T.; Malm, A. Inhibitory effect of 1,2,4-triazole-ciprofloxacin hybrids on Haemophilus parainfluenzae and Haemophilus influenzae biofilm formation in vitro under stationary conditions. Res. Microbiol. 2016, 167, 647-654. [CrossRef] 
38. Kosikowska, U.; Malm, A.; Pitucha, M.; Rajtar, B.; Polz-Dacewicz, M. Inhibitory effect of N-ethyl-3-amino-5oxo-4-phenyl-2,5-dihydro-1H-pyrazole-1-carbothioamide on Haemophilus spp. planktonic or biofilm-forming cells. Med. Chem. Res. 2014, 23, 1057-1066. [CrossRef]

39. Černohorská, L.; Votava, M. Antibiotic synergy against biofilm-forming Pseudomonas aeruginosa. Folia Microbiol. 2008, 53, 57-60. [CrossRef]

40. Sekiya, R.; Karakida, K.; Arai, T.; Sato, Y.; Sakamoto, Y.; Kanai, N.; Maruyama, R.; Kaneko, A. In vitro inhibitory effects of various antimicrobial and antifungal agents on biofilm formation of microorganisms isolated from odontogenic infections. Oral Ther. Pharmacol. 2010, 29, 69-76.

Sample Availability: Samples of the compounds 34A, 39A, 41A, 47A, 51A, 52A, 54A, 56A-60A, 64A and 19B-24B, 26B, 29B, 33B, 34B are available from the authors.

(C) 2019 by the authors. Licensee MDPI, Basel, Switzerland. This article is an open access article distributed under the terms and conditions of the Creative Commons Attribution (CC BY) license (http:/ / creativecommons.org/licenses/by/4.0/). 